\title{
Prenatal exposure to a maternal low-protein diet programmes a preference for high-fat foods in the young adult rat
}

\author{
Leanne Bellinger, Christina Lilley and Simon C. Langley-Evans* \\ Centre for Reproduction and Early Life, School of Biosciences, University of Nottingham, Sutton Bonington, \\ Loughborough LE12 5RD, UK
}

(Received 19 January 2004 - Revised 14 May 2004 - Accepted 18 May 2004)

\begin{abstract}
Nutrient restriction in pregnancy has been shown to programme adult obesity. Modulation of feeding behaviour may provide a mechanism through which obesity may be programmed. Pregnant Wistar rats were fed either a control diet or a low-protein (LP) diet throughout gestation. Their offspring were allocated to a self-selected-diet protocol to assess appetite and food preferences at 12 and at 30 weeks of age. Self-selection of high-fat, high-protein or high-carbohydrate foods by 12 -week-old rats indicated that the prenatal environment influenced feeding behaviour. Both male and female offspring of LP-fed mothers consumed significantly more of the high-fat $(P<0 \cdot 001)$ and significantly less $(P<0.02)$ of the high-carbohydrate food than the control animals. Female, but not male, offspring of LP-fed rats failed to adjust food intake to maintain a constant energy intake and had higher fat $(P<0 \cdot 005)$ and energy intakes $(P<0 \cdot 05)$ than control female rats. At 30 weeks of age there were no differences in the pattern of food selection between the two groups of animals. Male offspring of LP-fed rats had significantly more gonadal fat than control animals $(P<0 \cdot 05)$, but analysis of total body fat content indicated that there was no significant difference in overall adiposity. The present study suggests that in young adults at least, early life exposure to undernutrition determines a preference for fatty foods. Maternal nutrition may thus promote changes in systems that are involved in control of appetite or the perception of palatability.
\end{abstract}

Programming: Appetite: Obesity: Rat: Feeding behaviour

A range of epidemiological and experimental studies suggest that adult anatomy, physiology and metabolism may be programmed in part through exposure to an adverse nutritional environment in utero (Langley-Evans, 2001; Barker, 2003). Large retrospective cohort studies indicate that crude markers of maternal undernutrition during pregnancy are associated with increased risk of the metabolic syndrome (Eriksson et al. 2003) and the development of obesity (Law et al. 1992; Valdez et al. 1994; Curhan et al. 1996; Ravelli et al. 1999). Young adult men exposed to intra-uterine famine in early to mid-gestation during the Dutch Hunger Winter of 1944 were twice as likely to become obese by the age of 19 years than men born after the famine, whilst those exposed in late gestation had a lower risk of obesity (Ravelli et al. 1976).

In contrast, other studies show no significant association of fetal growth indicators with later obesity risk (Paz et al. 1993). Stunting of growth through undernutrition in infancy may carry a greater risk for fat deposition than fetal undernutrition (Martorell et al. 2001). The evidence linking prenatal undernutrition to programming of adult obesity in human subjects should therefore be viewed as limited and contradictory. Studies of animal models are likely to be of greater use in terms of assessing the strength of any association, the impact of the timing of undernutrition and the nature of the mechanisms involved.

In animals, any imbalance of nutrient intake, such that one or more nutrients is limiting, will produce adaptive responses in the developing fetus (Dahri et al. 1991; Langley-Evans et al. 1996; Langley-Evans, 2001; Bergel \& Belizan, 2002; Gambling et al. 2003). Whilst these metabolic adaptations ensure the immediate survival of the animal in a less than optimal fetal environment, long-term modifications to organ structure, hormone responsiveness or gene expression may predispose to metabolic disorders in later life.

In general, animal models of nutritional programming demonstrate that prenatal dietary restrictions lead to an increase in adult conditions that are associated with obesity or increased adiposity, in particular hypertension, glucose intolerance and insulin resistance (Dahri et al. 1991; Langley-Evans et al. 1996; Petry et al. 2001; Bergel \& Belizan, 2002; Gambling et al. 2003). To date, very few studies in rodents have evaluated the impact of early exposure to undernutrition on body composition. Food restriction in pregnant rats induces greater weight gain in the offspring, particularly when combined with high-fat feeding in adulthood (Jones \& Friedman, 1982; Jones et al. 1983; Anguita et al. 1993). Such effects appear to be genderspecific, although no consistent pattern is apparent. 
One mechanism through which variation in risk of obesity might be programmed is through modulation of feeding behaviour. Vickers et al. (2000) have demonstrated that severe restriction of maternal food intake in pregnancy results in offspring that are hyperphagic, have reduced physical activity (Vickers et al. 2003) and that develop profound obesity when provided with a hyperenergetic diet. A preliminary study by McCarthy et al. (1994) showed gender-specific effects on appetite when rats subject to prenatal protein restriction were provided with a free choice of single macronutrient feeds. Male offspring had an increased preference for fat, whilst their female littermates consumed less fat and more protein than control animals. The present paper aims to assess the feeding behaviour and body composition of male and female animals subject to protein restriction during fetal development.

\section{Materials and methods}

\section{Chemicals and reagents}

All chemicals and reagents were of reagent grade and were purchased from Fisher Scientific (Loughborough, Leics., UK).

\section{Animals}

Experiments described in the present paper were performed under licence from the Home Office in accordance with the 1986 Animals Act. Rats were housed in plastic boxes with a $12 \mathrm{~h}$ light-dark cycle at a temperature of $20 \pm 2^{\circ} \mathrm{C}$. The rats had free access to food and water at all times. Ten virgin female Wistar rats (Harlan Ltd, Belton, Leics., UK) were mated when they weighed $180-220 \mathrm{~g}$. Upon confirmation of mating by the appearance of a semen plug on the cage floor, the rats were allocated to be fed a control diet $(180 \mathrm{~g}$ casein $/ \mathrm{kg}$ diet, $n$ 5) or a low-protein (LP, $90 \mathrm{~g}$ casein $/ \mathrm{kg}$ diet, $n$ 5) diet, as described previously (Langley-Evans et al. 1994). The diets differed in their methionine:casein ratios, which were 1:36 in the control diet and 1:18 in the LP diet. The full composition of the diets is described elsewhere (Langley-Evans et al. 1994). The diets were isoenergetic, the difference in energy content between the control and LP diets being made up with additional carbohydrate (starch-sucrose $(2: 1, \mathrm{w} / \mathrm{w}))$.

The rats were fed the semi-synthetic diets until they delivered pups at $22 \mathrm{~d}$ gestation. All animals were then transferred to a standard laboratory chow diet (rat and mouse diet; B\&K Universal Ltd, Hull, UK) and the litters were culled to a maximum of eight pups within $12 \mathrm{~h}$ of delivery. This minimised variation in nutrition during the suckling period. Analysis of stomach contents from culled neonates indicated that protein content of milk did not differ significantly between control and LP groups (control 88.5 (SD 4.4), LP 79.9 (SD 4.0) g protein/l; NS). The offspring from the two groups therefore differed only in terms of their prenatal dietary experience.

At 4 weeks of age all offspring were weaned onto standard chow diet. At 12 weeks of age the animals from each maternal dietary group were divided into two subgroups. One group (where possible, two male and two female offspring from each litter) were allocated to a self-selecteddiet protocol to assess appetite and food preferences. The remaining animals had chow intake assessed over a $3 \mathrm{~d}$ period and were then retained until 30 weeks of age, when they underwent the self-selected-diet trial.

\section{Self-selected-diet trial}

Animals were singly housed and provided with free access to three different food sources. This enabled determination of their preference for a high-protein food, a high-carbohydrate food or a high-fat food (for details of compositions, see Table 1). The different foods were colour-coded to allow for collection and weighing of waste food to allow determination of intake to within $0.5 \mathrm{~g}$. All three foods were provided as balls weighing $60-100 \mathrm{~g}$, which were placed in the cage in random positions each day. The rats were allowed to become accustomed to the self-selection regimen for $2 \mathrm{~d}$ and then food intake was monitored at $12 \mathrm{~h}$ intervals over a period of $72 \mathrm{~h}$. Preliminary work had suggested that a measurement period of this duration was optimal to obtain an estimate of daily food intake in mature rodents. The results in the present paper are presented as the average intake per $\mathrm{d}$ for each rat, normalised for body weight ( $\mathrm{g}$ food intake/d per $\mathrm{kg}$ body weight). Given the known nutrient content of the three food sources, the macronutrient intakes of each animal were calculated from the food intake data.

All animals were weighed at the beginning and end of the self-selection period. From the weight gain and food intake data it was possible to determine energetic efficiency ( $\mathrm{g}$ weight gained/MJ energy consumed) and feed conversion rate ( $\mathrm{g}$ weight gained/g food consumed).

At the end of the self-selection period the rats were killed using a rising concentration of $\mathrm{CO}_{2}$ and cervical dislocation. Fat was dissected from three discrete depots (gonadal fat, perirenal fat and intrascapular fat (brown and white adipose tissue)) and accurately weighed. All material was returned to the carcass, which was then frozen at $-20^{\circ} \mathrm{C}$ before chemical analysis of whole body composition.

Table 1. Composition of postnatal self-selection foods $(\mathrm{g} / \mathrm{kg} \text { diet })^{\star}$

\begin{tabular}{lccc}
\hline Food... & High-fat & High-protein & High-CHO \\
\hline Maize oil & 100 & 100 & 100 \\
Lard & 295 & & \\
Casein & 200 & 485 & 200 \\
Maize starch & 220 & 220 & 515 \\
Sucrose & 100 & 100 & 100 \\
Cellulose & 50 & 50 & 50 \\
AIN-76 vitamin mix & 5 & 5 & 5 \\
AIN-76 mineral mix & 20 & 20 & 20 \\
DL-Methionine & 10 & 10 & 10 \\
Fat (\% energy) & 39.5 & 10.0 & 10.0 \\
Protein (\% energy) & 20.0 & 48.5 & 20.0 \\
Carbohydrate (\% energy) & 32.5 & 32.5 & 62.0 \\
Energy (MJ/kg) & 25.12 & 19.24 & 20.68 \\
\hline
\end{tabular}

$\mathrm{CHO}$, carbohydrate.

* Dry ingredients for the high-protein and high- $\mathrm{CHO}$ diets were mixed and then bound together through the addition of water. The diets were then dried at $60^{\circ} \mathrm{C}$ for $48 \mathrm{~h}$. The high-fat diet ingredients were mixed dry. All diets were stored at $-40^{\circ} \mathrm{C}$ until used. The energy content was determined by bomb calorimetry. 


\section{Analysis of carcass composition}

Whole carcass composition was determined in the offspring killed following study at 12 weeks of age. Thirty-week-old animals were not studied, as analysis of discrete fat depots indicated no significant differences in white adipose tissue deposition between the maternal dietary groups. The whole carcasses were oven-dried to determine body water content, as previously described (Langley \& York, 1990). The dried carcasses were homogenised and sampled for estimation of $\mathrm{N}$ content using the Kjehldahl method and for fat content by Soxhlet extraction, as previously described (Langley \& York, 1990).

\section{Statistical analysis}

Results are presented as mean values with their standard errors throughout the paper. All data were analysed using two- or three-way ANOVA as appropriate, followed by a least significance difference test as a post hoc test. As multiple pups from the same dam were included in the experimental groups, litter of origin was included as a covariate in all analyses. Probability $\leq 5 \%$ was accepted as statistically significant.

\section{Results}

All dams in the present study were of similar weight at mating and no significant differences were noted between the control and LP groups with regard to weight gain or food intake at any stage of pregnancy (results not shown). Litter size was unaffected by maternal protein restriction (control 14 (SEM 2), LP 12 (SEM 3) pups per litter). Pups from the two groups were of similar weight at birth, a finding consistent with previous studies (Langley-Evans, 2001), and remained of similar weight between birth and weaning (results not shown).

Intake of standard chow diet was monitored in offspring from the two maternal dietary groups at 12 weeks of age (Fig. 1). When normalised for body weight, female rats consumed more food than male rats, but this difference was less marked in the LP group. Female LP-exposed rats consumed significantly less chow than control animals $(P<0 \cdot 01)$. Feed conversion rates were similar in male and female rats fed chow and no significant difference between control and LP-exposed animals was noted (control male $0 \cdot 13$ (SEM 0.02), LP-exposed male $0 \cdot 12$ (SEM 0.03), control female 0.10 (SEM 0.03), LP-exposed female 0.07 (SEM $0 \cdot 03) \mathrm{g}$ weight gained/g food intake).

When 12-week-old rats were allowed to self-select their diet, significant differences in food preferences were observed. In general, female rats consumed more of the high-fat food and less of the carbohydrate-rich food than did male rats (Fig. 2(A)). Maternal diet influenced food selection in both male and female rats, with LP-exposed animals consuming significantly more (female $65 \%$ more, male $20 \%$ more; $P<0.01$ ) of the high-fat and significantly less (female $65 \%$ less, male $40 \%$ less; $P<0.01$ ) of the high-carbohydrate food than the control animals. In all groups, selection of the protein-rich food was low relative to the high-fat and

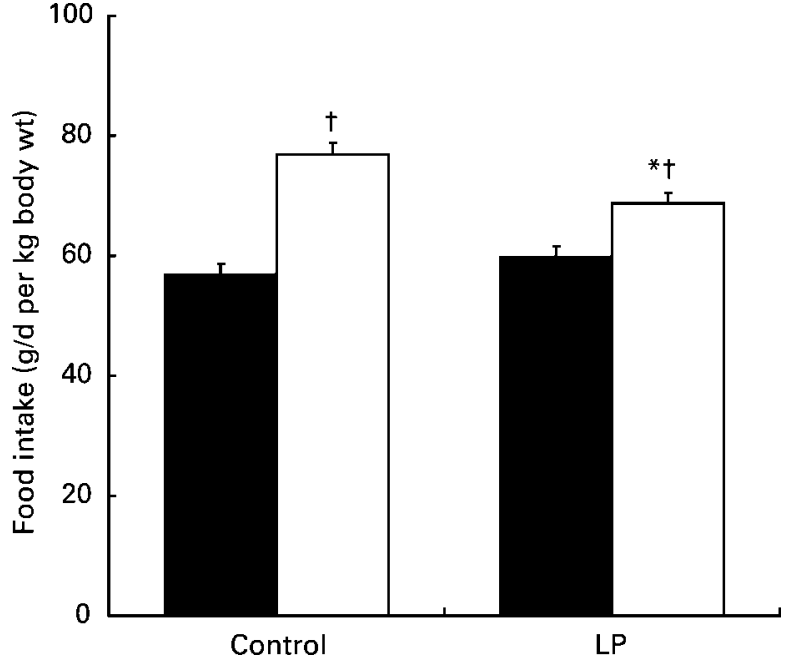

Fig. 1. Intake of standard laboratory chow diet by 12 -week-old rats. 口, Male; $\square$, female. For details of procedures, see p. 514. Values are means with their standard errors shown by vertical bars (lowprotein (LP)-exposed female rats $n 5$, control female rats $n 7$, LP-exposed male rats $n 6$, control male rats $n 12)$. There were significant effects (two-way ANOVA) of gender $(P<0.001)$ and gender $\times$ maternal diet $(P=0.001)$. Mean value was significantly different from that of the control group of the same gender: ${ }^{\star} P<0.05$. Mean values were significantly different from those of male rats in the same dietary group: $\dagger P<0.05$.

high-carbohydrate foods, contributing $2-4 \%$ to total food intake. Total food intake was similar in control and LP-exposed male rats, but LP-exposed female rats consumed significantly more food than the control animals (control 86.0 (SEM 4.0), LP 103.0 (SEM 5.0) g food/d per $\mathrm{kg}$ body weight; $P<0.05)$. When considered as intakes of the macronutrients (Fig. 3(A)), it was apparent that the animals were largely able to regulate their intake of nutrients, despite variation in the food source consumed. There was no significant difference in nutrient intakes of male LP-exposed rats compared with control animals. LP-exposed female rats had a higher fat intake than LP-exposed male rats and intake also differed significantly from control female rats $(P<0.05)$. Intakes of carbohydrate and protein were similar between the groups. The increased fat intake of the LP-exposed female rats was reflected in a significantly higher intake of energy $(P<0 \cdot 05$; Table 2$)$. Feed conversion rates and energy efficiency were not influenced by exposure to maternal LP diets in utero. The feed conversion of all animals on the self-selection protocol was greater than that of their littermates fed chow $(P<0.001)$.

When the littermates of these animals were studied at 30 weeks of age, the difference in the pattern of food selection observed earlier was absent. As shown in Fig. 2(B), although female rats still consumed more of the high-fat food than male rats, there were no significant differences between control and LP-exposed animals. Analysis of nutrient (Fig. 3(B)) and energy (Table 2) intakes indicated that female rats consumed significantly more energy, protein, fat and carbohydrate than male rats, but, again, intakes by control and LP-exposed rats were similar. Although LP-exposed female rats tended to have lower energetic efficiency and feed conversion ratio than control 
(A)

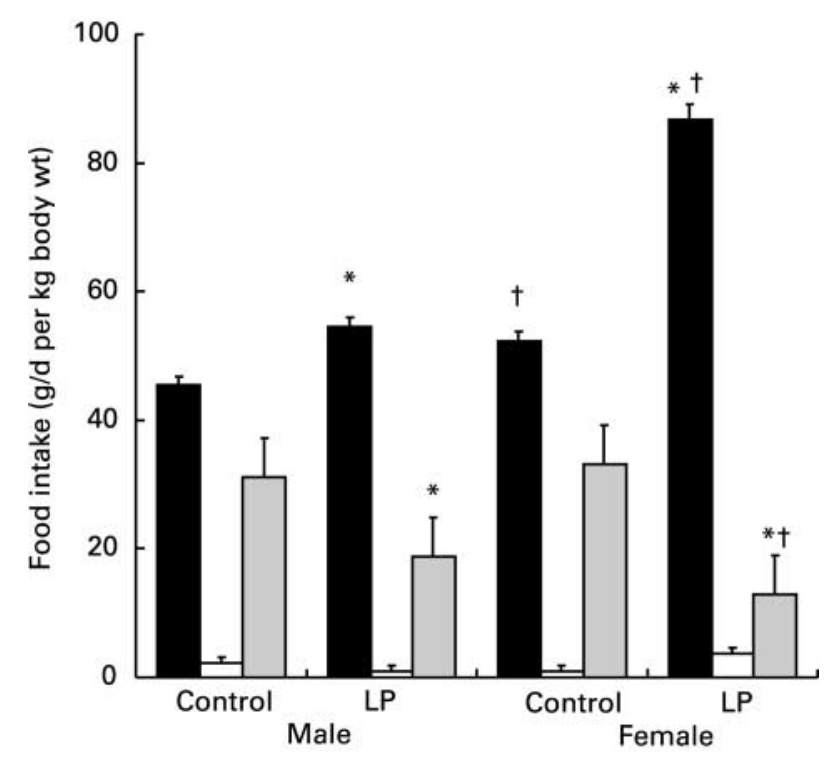

(B)

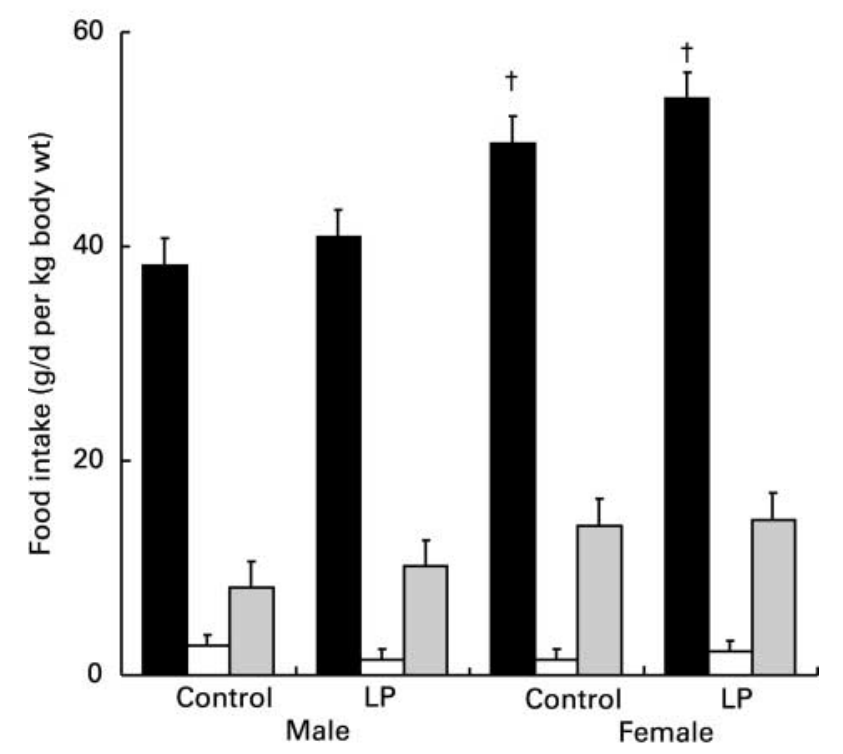

Fig. 2. Self-selection of high-fat, high-carbohydrate and high-protein foods by rats exposed to control or low-protein (LP) diets in utero. 口, Fat; $\square$, protein, $\square$, carbohydrate. For details of foods and procedures, see Table 1 and p. 514. (A), 12-week-old rats: values are means with their standard errors shown by vertical bars (LPexposed female rats $n 5$, control female rats $n 9$, LP-exposed male rats $n 6$, control male rats $n 11)$. There were significant effects (two-way ANOVA) of maternal diet $(P=0.001)$, gender $(P=0.002)$ and gender $\times$ maternal diet $(P=0.045)$ on consumption of the highfat food. There was a significant effect of maternal diet on consumption of high-carbohydrate food $(P=0.013)$. Mean values were significantly different from control rats of the same gender: ${ }^{*} P<0.05$. Mean values were significantly different from male rats within the same maternal dietary group: $\dagger P<0.05$. (B), 30-weekold rats: values are means with their standard errors shown by vertical bars (LP-exposed female rats $n 5$, control female rats $n 7$, LP-exposed male rats $n 6$, control male rats $n 12)$. There were significant effects (two-way ANOVA) of gender on consumption of high-fat food $(P=0.002)$. Mean values were significantly different from those of male rats within the same maternal dietary group: $\dagger P<0.05$.

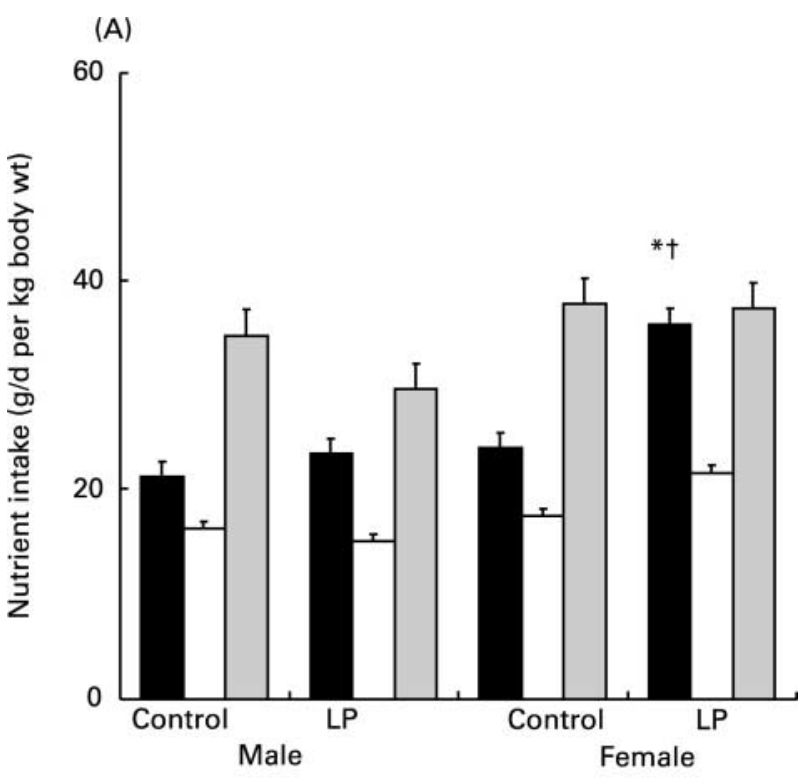

(B)

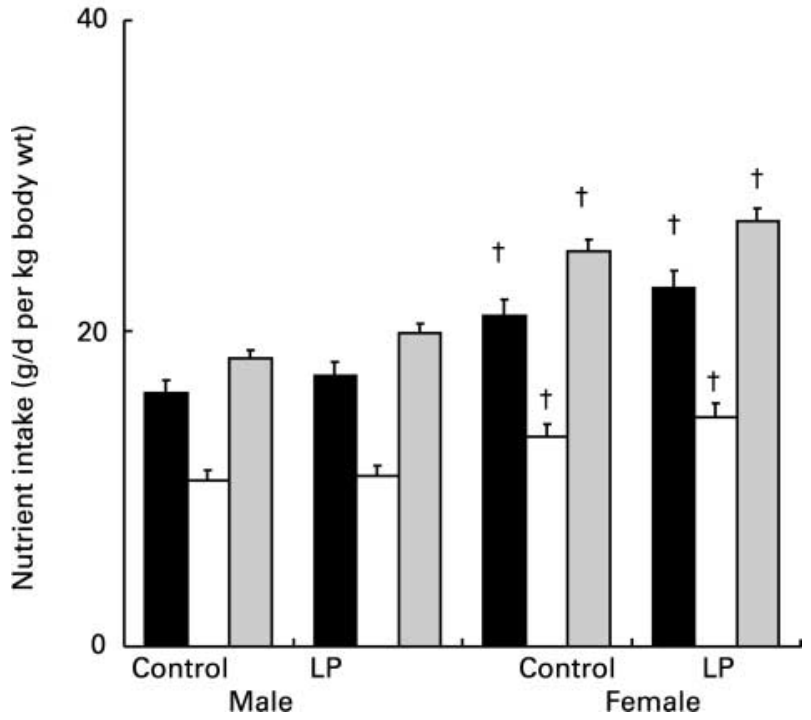

Fig. 3. Macronutrient intakes of rats exposed to control or low-protein (LP) diets in utero and allowed to self-select foods. $\mathbf{\square}$, Fat; $\square$, protein, , carbohydrate. For details of foods and procedures, see Table 1 and p. 514. (A), 12-week-old rats: values are means with their standard errors shown by vertical bars (LP-exposed female rats $n 5$, control female rats $n 9$, LP-exposed male rats $n 6$, control male rats $n$ 11). There were significant effects (two-way ANOVA) of maternal diet $(P=0.002)$, gender $(P=0.001)$ and gender $\times$ maternal diet $(P=0.023)$ on consumption of fat. There was a significant effect of gender on consumption of protein $(P<0.001)$. Mean value was significantly different from that of control rats of the same gender: ${ }^{\star} P<0.05$. Mean value was significantly different from that of male rats within the same maternal dietary group: $\dagger P<0.05$. (B), 30-week-old rats: values are means with their standard errors shown by vertical bars (LP-exposed female rats $n 5$, control female rats $n 7$, LP-exposed male rats $n$ 6 , control male rats $n$ 12). There were significant effects (two-way ANOVA) of gender on intakes of fat $(P<0.001)$, carbohydrate $(P<0.001)$ and protein $(P<0.001)$. Mean values were significantly different from those of male rats within the same maternal dietary group: $\dagger P<0.05$. 
Table 2. Energy intake, and energetic and feed efficiencies of rats fed self-selection foods at 12 and 30 weeks of age $\neq \S$ (Mean values with their standard errors)

\begin{tabular}{|c|c|c|c|c|c|c|c|c|}
\hline \multirow[b]{2}{*}{ Maternal diet } & \multirow[b]{2}{*}{ Age (weeks) } & \multirow[b]{2}{*}{ Gender } & \multicolumn{2}{|c|}{$\begin{array}{l}\text { Energy intake }(\mathrm{MJ} / \mathrm{d} \\
\text { per kg body wt)\| }\end{array}$} & \multicolumn{2}{|c|}{$\begin{array}{l}\text { Energy efficiency } \\
\text { (g wt gain/MJ) }\end{array}$} & \multicolumn{2}{|c|}{$\begin{array}{l}\text { Feed conversion } \\
\text { (g wt gain/g food) }\end{array}$} \\
\hline & & & Mean & SEM & Mean & SEM & Mean & SEM \\
\hline \multirow[t]{4}{*}{ Control } & 12 & $M$ & 1.83 & 0.08 & $9 \cdot 36$ & 0.96 & 0.22 & 0.02 \\
\hline & 12 & $\mathrm{~F}$ & $2 \cdot 02$ & 0.09 & 8.56 & 1.06 & 0.20 & 0.03 \\
\hline & 30 & M & $1 \cdot 18$ & 0.06 & $6 \cdot 12$ & 1.12 & 0.15 & 0.03 \\
\hline & 30 & $\mathrm{~F}$ & $1.56 \dagger$ & 0.07 & $4 \cdot 68$ & 1.46 & 0.11 & 0.04 \\
\hline \multirow{4}{*}{ Low-protein } & 12 & $\mathrm{M}$ & 1.78 & 0.11 & $10 \cdot 28$ & 1.29 & 0.25 & 0.03 \\
\hline & 12 & $\mathrm{~F}$ & $2 \cdot 52^{*} \dagger$ & 0.12 & $7 \cdot 22$ & 1.42 & 0.18 & 0.03 \\
\hline & 30 & M & 1.27 & 0.08 & 5.73 & 1.58 & 0.14 & 0.04 \\
\hline & 30 & $\mathrm{~F}$ & $1.69 \dagger$ & 0.09 & 2.51 & 1.73 & 0.06 & 0.04 \\
\hline
\end{tabular}

M, male; F, female

Mean value was significantly different from that of the female control group: * $P<0.05$

Mean values were significantly different from those of male rats in the same maternal diet group: $\dagger P<0.05$

$\ddagger$ For details of foods and procedures, see Table 1 and p. 514.

$\S$ For numbers of rats in each group see legends to Figs 2 and 3.

\| Energy intake was influenced by maternal diet $(P=0.041)$, gender $(P<0.001)$ and gender $\times$ diet interaction $(P<0.014)$ at 12 weeks, and by gender $(P<0.001)$ at 30 weeks.

females, this difference did not achieve statistical significance (Table 2).

Body weights of LP-exposed animals were similar to those of control animals at 12 weeks of age (Fig. 4). By 30 weeks of age, male offspring from the LP-exposed group were significantly lighter than control animals, but their female littermates were of equivalent weight to the control group. Fat depots were dissected from the perirenal, intrascapular and gonadal regions and assessed in proportion to body weight. The combined size of the three

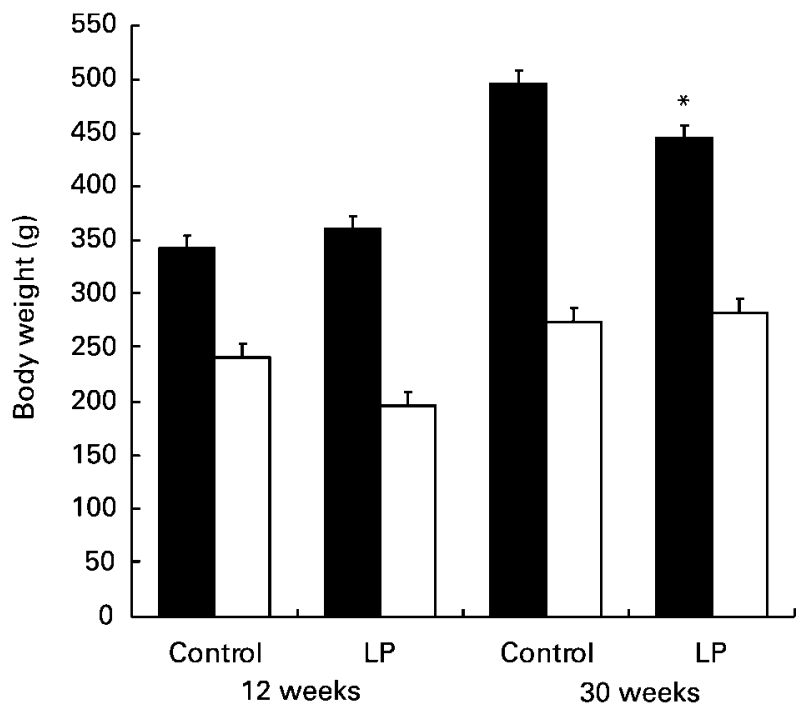

Fig. 4. Body weights of offspring at 12 and 30 weeks of age. Male, $\square$, female. For details of foods and procedures, see Table 1 and p. 514. At 12 weeks: low-protein (LP)-exposed female rats $n 5$, control female rats $n 9$, LP-exposed male rats $n 6$, control male rats $n$ 11. At 30 weeks: LP-exposed female rats $n 5$, control female rats $n 5$, LP-exposed male rats $n 6$, control male rats $n 12$. There were significant effects (three-way ANOVA) of age $(P<0.001)$, gender $(P<0.001)$ and age $\times$ gender $\times$ maternal diet $(P=0.017)$ on weight. Mean value was significantly different from that of control rats of the same age: ${ }^{\star} P<0.05$. depots did not differ significantly between the two groups at 12 weeks (Fig. 5(A)) or 30 weeks of age (Fig. 5(B)). At 12 weeks, however, LP-exposed male rats had significantly more gonadal fat than control animals $(P<0.05)$. Female rats had significantly larger intrascapular fat depots than male rats $(P<0 \cdot 0)$. At 30 weeks, female rats still had larger intrascapular depots than male rats. LPexposed female rats had significantly more brown adipose tissue at the site than control animals $(P<0.05)$. Total body composition was determined chemically in homogenised carcasses from the animals culled at 12 weeks of age. Although analysis of fat stored at specific depots indicated that there might be a difference in abdominal fat deposition, no significant differences in whole body fat content were noted between the control and LP-exposed animals (Fig. 6).

\section{Discussion}

The hypothesis for the present study was that exposure to maternal undernutrition in early life would programme a specific preference for energy-dense foodstuffs and hyperphagia. Such a finding would be important in the context of the fetal programming of obesity, as other workers have demonstrated that, in rats, early life undernutrition programmes profound obesity in response to hyperenergetic feeding (Jones et al. 1983; Vickers et al. 2000). The main findings of the present study appeared to be, to some extent, consistent with such a hypothesis, as it was noted that when switched from a standard laboratory chow diet, designed to prevent the development of obesity in laboratory rodents, 12-week-old rats exposed to maternal undernutrition during fetal development self-selected a mainly fat-based diet to a greater extent than control animals exposed to a protein-replete diet in utero. These findings partially agree with those of McCarthy et al. (1994). Female animals from the LPexposed group were hypophagic when provided with chow, but became hyperphagic relative to control values when allowed to self-select their diets. Interestingly, the same protocol applied to the littermates of these animals at the 


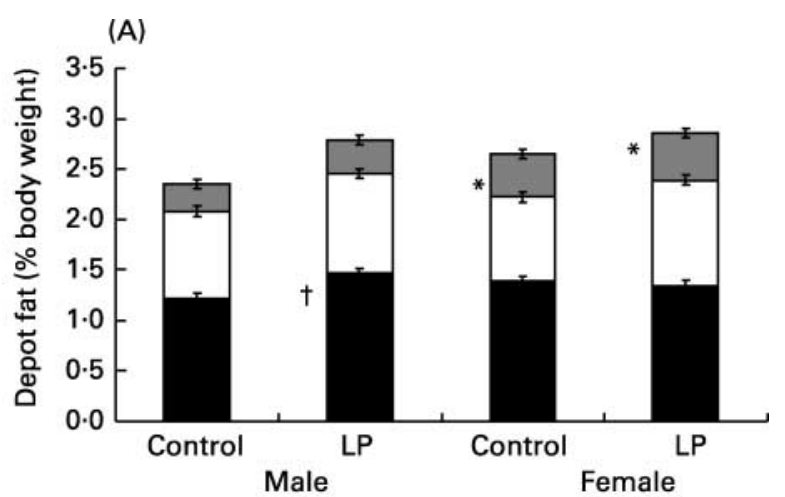

(B)

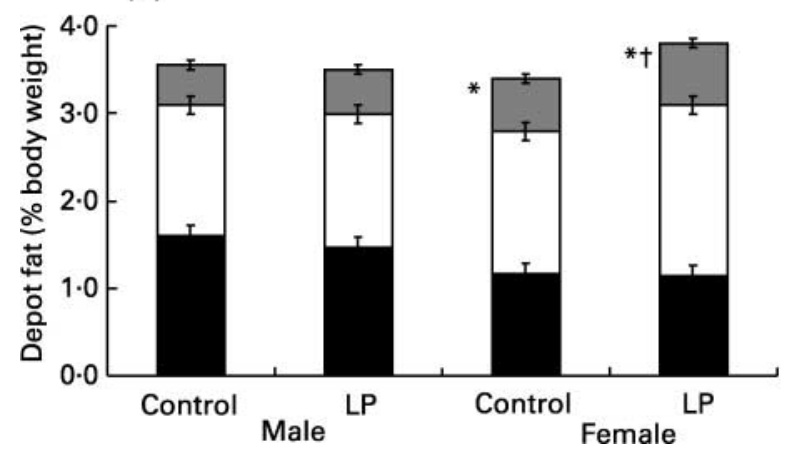

Fig. 5. Size of discrete adipose tissue depots. For details of foods and procedures, see Table 1 and p. 514. $\mathbf{~ , ~ G o n a d a l ; ~} \square$, perirenal, - intrascapular. (A), 12 weeks of age: values are means with their standard errors shown by vertical bars (LP-exposed female rats $n$ 5 , control female rats $n 9$, LP-exposed male rats $n 6$, control male rats $n$ 11). There were significant effects (two-way ANOVA) on gonadal fat depot size in male rats of maternal diet $(P=0.01)$ and on the white adipose component of the intrascapular depot by gender $(P=0.007)$. Mean values were significantly different from those of male rats in the same maternal diet group: ${ }^{\star} P<0.05$. Mean value was significantly different from that of male control rats: $\dagger P<0.05$. (B), 30 weeks of age: values are means with their standard errors shown by vertical bars (LP-exposed female rats $n 5$, control female rats $n 7$, LP-exposed male rats $n 6$, control male rats $n 12$ ). There were significant effects (two-way ANOVA) on the brown adipose tissue component of the intrascapular depot of gender $(P=0.002)$ and maternal diet $(P=0.027)$. Mean values were significantly different from those of male rats in the same maternal diet group: ${ }^{*} P<0.05$. Mean value was significantly diffferent from that of male control rats: $\dagger P<0.05$

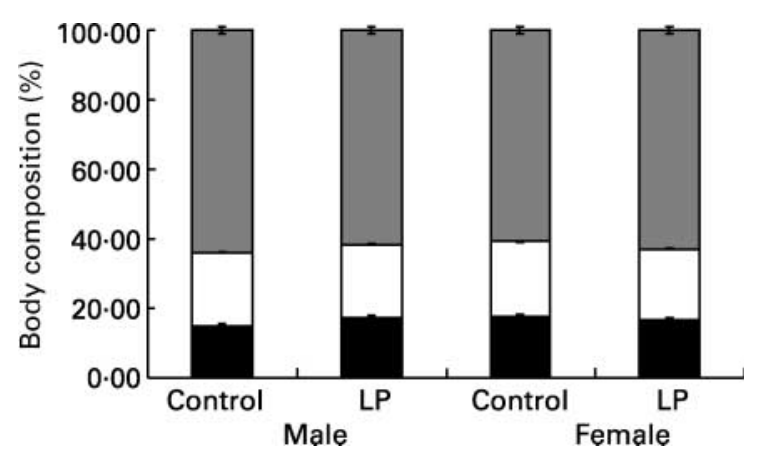

Fig. 6. Whole carcass composition at 12 weeks of age. For details of foods and procedures, see Table 1 and p. 514. घ, Fat; $\square$, protein; , water. Values are means with their standard errors shown by vertical bars (LP-exposed female rats $n 5$, control female rats $n$ 9, LP-exposed male rats $n 6$, control male rats $n 11)$. There were no significant effects of maternal diet or gender. age of 30 weeks did not produce the same behavioural responses.

Animal models of programming are essential in the elucidation of molecular and physiological mechanisms that link fetal nutritional exposures to long-term disease risk. Most importantly, animal models demonstrate the biological plausibility of the widely criticised (Huxley et al. 2002) programming hypothesis. The specific nature of the nutrient manipulations applied to rodent pregnancies are often a point of contention, with some approaches being designed to test the effects of particular nutrient restrictions or excesses, whilst others are aimed solely at inducing fetal growth retardation. Some of the latter may be criticised as non-physiological, whilst the former may be challenged on the basis of applicability to human nutrition. The LP diet used in the present study has been criticised on the basis of its high methionine content and the possible impact this may have on maternal methionine-homocysteine metabolism. This conjecture was raised by Rees (2002), but as yet has little supporting evidence. Indeed, other LP diets with much lower methionine content exert the same effects on blood pressure and renal development (Vehaskari et al. 2001; Woods et al. 2004) and our own studies of a LP, low-methionine diet indicated that methionine could not explain key programming effects of the LP diet (LangleyEvans et al. 2003). More recently it has been shown that exposure of rat embryos to high concentrations of homocysteine did not have harmful effects that would be consistent with programming (J McConnell, personal communication). However, it should be acknowledged that the effects noted in the present study may not be attributable to protein per se. We have previously noted that the overall matrix in which a LP diet is delivered is an important determinant of outcomes (Langley-Evans, 2000).

Twelve-week-old female rats exposed to LP diet in utero fed standard laboratory chow were hypophagic when compared with the control group, whilst the food intake of male rats was not influenced by prenatal factors. This is in direct contrast to the results of Vickers et al. (2000), who reported that rats subject to undernutrition in utero were hyperphagic. The protocol applied by Vickers et al. (2000) during pregnancy imposes a marked intrauterine growth restriction that is not observed with the LP diet model. As such, the long-term effects that have been reported may to some extent reflect the pups' ability to feed, maternal-neonatal interactions and the postnatal growth rate. This is perhaps analogous to the observations of Martorell et al. (2001) in human subjects, where growth in infancy was a powerful predictor of later obesity.

Earlier reports have suggested that undernutrition in utero may induce obesity in rodents regardless of the postnatal diet (Jones \& Friedman, 1982; Anguita et al. 1993). This was not observed in the present study. All our measurements of body composition and adipose tissue deposition primarily represent the pattern and extent of fat deposition in chow fed animals, as exposure to the self-selection diet was limited to just $5 \mathrm{~d}$. Whilst there was some evidence that LP-exposed male rats deposited more gonadal fat, none of the animals could be described as obese.

The key issue identified by Vickers et al. (2000), however, is that challenge with a hyperenergetic diet elicits 
obesity in programmed offspring. This was also the finding of Jones et al. (1983) and Petry et al. (1997). McCarthy et al. (1994) noted that in both male and female LPexposed rats following the self-selected diet there was a significant increase in deposition of abdominal fat. Further studies in our laboratory will utilise the high-fat food preferentially selected by the animals as the sole food source to examine its obesogenic effect. This work will also need to consider effects on the glucose-insulin axis, and important endocrine indicators including leptin, in order to assess metabolic adaptations to high-fat feeding.

The outcomes of such a trial are likely to depend on the timing of the dietary manipulations. First, the timing of nutrient restriction in pregnancy may be critical in establishing feeding behaviour and the metabolic response to hyperenergetic diets. Results from the Dutch Hunger Winter (Ravelli et al. 1976) suggested that exposure of the human fetus to undernutrition in early gestation increased later obesity risk, whilst exposure in later gestation produced a relative resistance to obesity. The same may well apply within animal models. The timing of the introduction of the postnatal diet may also be critical, as indicated by our present finding that the high-fat preference of the LP-exposed rats was not present at the age of 30 weeks. This provides an interesting contrast to early work on cafeteria feeding of rodents (Rothwell \& Stock, 1982). This well-established method of inducing diet-induced obesity involves feeding highly palatable foods to overcome normal regulation of appetite. Generally speaking, this is more effective in older rats than younger animals, in contrast to the present observation. However, older reports also suggest that high-fat feeding to induce obesity is more effective if introduced at weaning than later in life (Kanarek \& Hirsch, 1977). A trial of longer duration will also be important to assess better the capacity of the animals to adjust energy intake in response to the novel and highly palatable dietary stimulus. It is known from the study of McCarthy et al. (1994), however, that the differences in food preferences between control and LP-exposed rats persist for up to $100 \mathrm{~d}$.

The palatability of the foods used in the present trial is clearly an important factor in interpreting the results. All animals preferred the high-fat food, which may in part reflect both the greater acceptability of fat and also the texture and softer consistency of the food ball compared with the other sources. In addition to appetite control systems, the processes that govern taste and smell and hence the palatability of foodstuffs may also be subject to programming influences and Bray (2000) has also identified them as potential mediators of appetite and weight control. Preliminary work has demonstrated that LP-exposure in fetal life determines the hypothalamic expression of taste and olfactory receptors (Langley-Evans et al. 2004). In rats, these senses are closely linked and are controlled by the amygdala, pre-frontal cortex and cingulate cortex (Sakai \& Imada, 2003). It is possible that the development of these structures is altered by intra-uterine factors. Plagemann et al. (2000) have demonstrated that feeding a LP diet throughout pregnancy and lactation alters the size and neuronal density of hypothalamic structures involved in the regulation of feeding.
The present study suggests that in young adults at least, early life exposure to undernutrition determines a preference for fatty foods. This is consistent with the view of Vickers et al. (2003), who reported that prenatal undernutrition leads to 'couch potato syndrome', in which over-consumption of a high-fat diet and low physical activity promotes the development of obesity. Further studies will investigate the mechanistic basis of this important finding.

\section{Acknowledgements}

The authors thank Mr R. Plant and Mr D. Howson for technical assistance. L. B. is supported by a Biotechnology and Biological Sciences Research Council studentship.

\section{References}

Anguita RM, Sigulem DM \& Sawaya AL (1993) Intrauterine food restriction is associated with obesity in young rats. J Nutr 123, $1421-1428$.

Barker DJP (2003) The developmental origins of adult disease. Eur J Epidemiol 18, 733-736.

Bergel E \& Belizan JM (2002) A deficient maternal calcium intake during pregnancy increases blood pressure of the offspring in adult rats. Br J Obstet Gynaecol 109, 540-545.

Bray GA (2000) Afferent signals regulating food intake. Proc Nutr Soc 59, 373-384.

Curhan GC, Chertow GM, Willett WC, Spiegelman D, Colditz GA, Manson JE, Speizer FE \& Stampfer MJ (1996) Birth weight and adult hypertension and obesity in women. Circulation 94, 1310-1315.

Dahri S, Snoeck A, Reusens-Billen B, Remacle C \& Hoet JJ (1991) Islet function in offspring of mothers on low protein diet during gestation. Diabetes 40, 115-120.

Eriksson JG, Forsen TJ, Osmond C \& Barker DJ (2003) Pathways of infant and childhood growth that lead to type 2 diabetes. Diabetes Care 26, 3006-3010.

Gambling L, Dunford S, Wallace DI, Zuur G, Solanky N, Srai SK \& McArdle H (2003) Iron deficiency during pregnancy affects postnatal blood pressure in the rat. $J$ Physiol 552, 603-610.

Huxley R, Neil A \& Collins R (2002) Unravelling the fetal origins hypothesis: is there really an inverse association between birthweight and subsequent blood pressure? Lancet 360, 659-665.

Jones AP \& Friedman MI (1982) Obesity and adipocyte abnormalities in offspring of rats undernourished during pregnancy. Science 215, 1518-1519.

Jones AP, Simson EL \& Friedman MI (1983) Gestational undernutrition and the development of obesity in rats. $J$ Nutr 114 , $1482-1484$.

Kanarek RB \& Hirsch E (1977) Dietary induced over-eating in experimental animals. Fed Proc 36, 154-158.

Langley SC \& York DA (1990) The effects of the antiglucocorticoid RU486 on the development of obesity in the obese $\mathrm{fa} / \mathrm{fa}$ Zucker rat. Am J Physiol 259, R539-R542.

Langley-Evans SC (2000) Critical differences between two low protein diet protocols in the programming of hypertension in the rat. Int J Food Sci Nutr 51, 11-17.

Langley-Evans SC (2001) Fetal programming of cardiovascular function through exposure to maternal undernutrition. Proc Nutr Soc 60, 505-513.

Langley-Evans SC, Bellinger L, Sculley DV, Langley-Evans AJ \& McMullen S (2004) Manipulation of the maternal diet in rat pregnancy: different approaches to the demonstration of 
the programming principle. In Early Life Origins of Adult Health and Disease, [M Wintour-Coghlan and JA Owens, editors]. Georgetown: Landes Biosciences Publishing (In the Press).

Langley-Evans SC, Makinson O \& McMullen S (2003) Renal programming by maternal low protein diets in the rat is not related to dietary methionine content. Pediatr Res 53, P402.

Langley-Evans SC, Phillips GJ \& Jackson AA (1994) In utero exposure to maternal low protein diets induces hypertension in weanling rats, independently of maternal blood pressure changes. Clin Nutr 13, 319-324.

Langley-Evans SC, Welham SJM, Sherman RC \& Jackson AA (1996) Weanling rats exposed to maternal low protein diets during discrete periods of gestation exhibit differing severity of hypertension. Clin Sci 91, 607-615.

Law CM, Barker DJP, Osmond C, Fall CHD \& Simmonds SJ (1992) Early growth and abdominal fatness in adult life. J Epidemiol Community Health 46, 184-186.

McCarthy HD, Pickard CL, Speed J \& Jackson AA (1994) Sexual dimorphism of macronutrient selection and regional adipose tissue accumulation following in utero exposure to maternal low protein diet. Proc Nutr Soc 53, 172A.

Martorell R, Stein AD \& Schroeder DG (2001) Early nutrition and later adiposity. $J$ Nutr 131, 874S-880S.

Paz I, Seidman DS, Danon YL, Laor A, Stevenson DK \& Gale R (1993) Are children born small-for-gestational-age at increased risk of short stature? Am J Dis Child 147, 337-339.

Petry CJ, Ozanne SE, Wang CL \& Hales CN (1997) Early protein restriction and obesity independently induce hypertension in year old rats. Clin Sci 93, 147-152.

Petry CJ, Dorling MW, Pawlak DB, Ozanne SE \& Hales CN (2001) Diabetes in male offspring of rat dams fed a reduced protein diet. Int J Exp Diabetes Res 2, 139-143.

Plagemann A, Harder T, Rake A, Melchior K, Rohde W \&
Dorner G (2000) Hypothalamic nuclei are malformed in weanling offspring of low protein malnourished rat dams. J Nutr 130, 2582-2589.

Ravelli AC, van der Meulen JH, Osmond C, Barker DJ \& Bleker OP (1999) Obesity at the age of $50 \mathrm{y}$ in men and women exposed to famine prenatally. Am J Clin Nutr 70, 811-816.

Ravelli G, Stein Z \& Susser MW (1976) Obesity in young men after famine exposure in utero and in early infancy. New Engl J Med 295, 349-353.

Rees WD (2002) Manipulating the sulfur amino acid content of the early diet and its implications for long-term health. Proc Nutr Soc 61, 71-77.

Rothwell NJ \& Stock MJ (1982) Effects of feeding a palatable "cafeteria" diet on energy balance on young and adult lean (+/?) Zucker rats. Br J Nutr 47, 461-471.

Sakai N \& Imada S (2003) Bilateral lesions of the insular cortex or of the prefrontal cortex block the association between taste and odor in the rat. Neurobiol Learn Mem 80, 24-31.

Valdez R, Athens MA, Thompson GH, Bradshaw BS \& Stern MP (1994) Birthweight and adult health outcomes in a biethnic population in the USA. Diabetologia 37, 627-631.

Vehaskari VM, Aviles DH \& Manning J (2001) Prenatal programming of adult hypertension in the rat. Kidney Int 59, $238-245$.

Vickers MH, Breier BH, Cutfield WS, Hofman PL \& Gluckman PD (2000) Fetal origins of hyperphagia, obesity, and hypertension and postnatal amplification by hypercaloric nutrition. Am J Physiol Endocrinol Metab 279, E83-E87.

Vickers MH, Breier BH, McCarthy D \& Gluckman PD (2003) Sedentary behavior during postnatal life is determined by the prenatal environment and exacerbated by postnatal hypercaloric nutrition. Am J Physiol 285, R271-R273.

Woods LL, Weeks DA \& Rasch R (2004) Programming of adult blood pressure by maternal protein restriction: Role of nephrogenesis. Kidney Int 65, 1339-1348. 